\title{
Programa Mais Educação: avanços e desafios para uma estratégia indutora da Educação Integral e em tempo integral
}

\section{More Education Program: breakthroughs and challenges for an inducing strategy of full time Integral Education}

\author{
Gesuína de Fátima Elias Leclerc ${ }^{1}$ \\ Jaqueline Moll ${ }^{2}$
}

\begin{abstract}
RESUMO
Este artigo compartilha parte dos debates sobre a estratégia de ampliação da jornada escolar na perspectiva da Educação Integral no ensino fundamental, engendrada pelo Programa Mais Educação, que é desenvolvido pelo Ministério da Educação em parceria com Estados e Municípios, desde 2008. Seu foco é a compreensão do modus operandi para a paulatina e progressiva reorganização da escola nessa perspectiva, materializado através dos macrocampos definidos no Decreto Presidencial 7083/2010. O foco constitui-se pelos apontamentos críticos e propositivos em relação à divisão da vida escolar em turnos e as ações necessárias para sua superação. Trata-se do olhar que capta, por um lado, o turno fixo, em que prevalecem as disciplinas tradicionais, que constituem o núcleo duro do currículo e, por outro, os contraturnos flexíveis, em que prevalecem as atividades que procuram tornar o "tempo escolar agradável". O trabalho tem como pano de fundo os movimentos realizados pelo Ministério da Educação na implicação de diferentes atores institucionais da educação brasileira na construção de uma pauta política e pedagógica em favor da Educação Integral.

Palavras-chave: Programa Mais Educação; Educação Integral; território; turno e contraturno.
\end{abstract}

1 Doutora em Educação pela Universidade Federal da Paraíba, Consultora da Organização dos Estados Ibero-americanos para o Ministério da Educação, Brasil.

2 Doutora em Educação pela Universidade Federal do Rio Grande do Sul (UFRGS), na qual também é docente e Colaboradora da Universidade de Brasília (UnB), Diretora de Currículos e Educação Integral do Ministério da Educação, Brasil. 


\begin{abstract}
This article shares part of the debates about the strategy to enlarge schooling day in an Integral Education perspective for Primary and Secondary Education. The strategy has been proposed by the More Education Program, which has been developed by The Ministry of Education in partnership with States and Municipalities, since 2008. Its focus is to find and propose a modus operandi for the progressive and continuous reorganization of the public school in that perspective according to the macro fields defined by the Presidential Decree 7083/2010. Our aim is to criticize the division of schooling life in shifts of studies and to propose some actions required for overcoming it. We consider, on one hand, the fixed main shift in which the traditional disciplines prevail and that constitutes the hard core of the curriculum; on the other hand, we also consider a flexible second shift in which the activities that can make the "schooling time pleasant" prevail. This paper has as background the efforts made by the Ministry of Education in order to regroup and motivate different institutional actors of Brazilian education in the construction of a political and pedagogical agenda in favor of integral education.
\end{abstract}

Keywords: More Education Program; Integral Education; territory; shift and after school activities.

\title{
Oferecer Educação Integral e em tempo integral como política pública: de quem é essa tarefa?
}

Todo relato sobre as origens do Estado parte da premissa de que "nós" - não nós leitores, mas algum nós genérico, tão amplo a ponto de não excluir ninguém - participamos de seu nascimento. Mas o fato é que o único "nós" que nós conhecemos - nós mesmos e as pessoas próximas a nós - nascem dentro do Estado; e nossos antepassados também nasceram dentro do Estado até onde possamos situar. O Estado existe antes de nós. (Até onde no passado conseguimos nos situar? No pensamento africano, o consenso é que depois de sete gerações não conseguimos mais distinguir entre história e mito.) (COETZEE, 2008, p. 7).

O lugar institucional em que nos situamos para desenvolver a temática da Educação Integral e em tempo integral é o Ministério da Educação, e o presente 
recorte decorre de um engajamento em uma tarefa específica, que é a implementação do Programa Mais Educação. Pela condição desse lugar institucional, mais do que discutir o papel do Estado como indutor de políticas públicas, à luz de conceitos e questões teóricas, cabe-nos o compromisso para demonstrar, por meio dessa implementação, qual tem sido o protagonismo do Estado, ao menos na esfera do Poder Executivo Federal, no campo da indução da Educação Integral e em tempo integral. Pela dificuldade desse compromisso deixamo-nos influenciar pelo problema apontado na epígrafe: o Governo Federal, esfera do Poder Executivo, é expressão par excellence do Estado, que existe antes de nós e cuja compreensão requer recuos geracionais.

Em nosso recuo destacamos a preocupação de Anísio Teixeira (2007, p. 100) em relação ao conceito de educação:

Temos, primeiro de tudo, de restabelecer o verdadeiro conceito de educação, retirando-lhe todo o aspecto formal, herdado de um conceito de escolas para o privilégio e, por isto mesmo, reguladas apenas pela lei e por toda sua parafernália formalística, e caracterizá-la, enfaticamente, como um processo de cultivo e amadurecimento individual, insusceptível de ser burlado, pois corresponde a um crescimento orgânico, humano, governado por normas científicas e técnicas, e não jurídicas, e a ser julgado sempre a posteriori e não pelo cumprimento formal de condições estabelecidas a priori.

Restabelecida esta maneira de conceituá-la, a educação deixará de ser campo de arbitrária regulamentação legal, que no Brasil vem fazendo dela um objeto de reivindicação imediata, por intermédio do miraculoso reconhecimento legal ou oficial. $\mathrm{O}$ fato de havermos confundido e identificado o processo educativo com um processo de formalismo legal levou a educação a ser julgada por normas equivalentes às da processualística judiciária que é, essencialmente, um regime de prazos e de normas, fixados, de certo modo, por convenção.

Desse modo, a Educação Integral é o modo de retomar o sentido desse “crescimento orgânico, humano", associado às múltiplas dimensões do desenvolvimento humano. Trata-se do reencontro com a análise de Anísio Teixeira (2007, p. 91) na qual, após argumentar sobre a "incapacidade da República 
para estender a educação a todos"3, apresenta o problema candente da escola de qualidade para todos, no contexto brasileiro nos anos 20 e 30 do século XX:

Quando na década de 1920 a 1930, começou a amadurecer mais a consciência política da Nação e se iniciou a batalha pelo voto secreto e livre, e esta batalha devia ser acompanhada (uma vez que não precedida) da óbvia contrapartida - a educação do povo.

Não se dirá que lhe tenha faltado completamente este eco, este reclamo educacional. Foi, com efeito, nesse período que a idéia de estender a educação a todos começou a medrar. Mas, de que modo?

Até então, os educadores com a indiferença das classes governantes, vinham mantendo uma escola pública de cinco anos, seguida de um curso complementar. Quando os políticos, entretanto, resolveram tomar conhecimento do problema, forçados pela conjuntura social do Brasil, a primeira revelação que não lhe era possível senti-lo em sua integridade, mas, apenas, sentir a necessidade de escamoteá-lo, patenteou-se na solução proposta: - reduzir as séries, para atingir maior número de alunos. E foi exatamente aqui, em São Paulo, em 1920, que houve a tentativa da escola primária de dois anos (!) que, embora combatida e, felizmente, malograda, passou a ser padrão inspirador de outras simplificações da educação brasileira (TEIXEIRA, 2007, p. 94).

Dentre as simplificações da educação brasileira, a questão do "encurtamento" do tempo diário letivo permanece como um desafio recrudescido, expresso no currículo escolar:

Encurtamos o período das aulas, encurtamos os professores. Nessa escola brasileira tudo pode ser dispensado: prédios, instalações, bibliotecas, professores... somente não pode ser dispensada a lista completa de matérias. Qualquer daquelas disciplinas têm de existir no currículo. Uma só que retiremos, porá abaixo todo o edifício de nossa cultura! Ai de quem pensa em tirar uma só daquelas línguas, ou fundir uma disciplina na outra!... (TEIXEIRA, 2007, p. 52).

3 Para aprofundar o tema ver Casemiro dos Reis Filho (1995) e Rosa Fátima de Souza (1998). 
Esse mesmo aspecto, o do encurtamento do tempo, é bem retratado na expressão "programa de menos a um maior número de alunos" (TEIXEIRA, 2007, p. 125):

A idéia de treinamento para o trabalho aliada à extensão do ensino a todos resultou, na prática, em um programa de menos a um maior número de alunos. Além da redução do curso primário, logo surgiu, para ampliar a matrícula, a inovação dos turnos escolares, ou seja, o funcionamento da escola em vários turnos, com redução do dia escolar e, por fim, a redução do período de formação dos professores. [...] A despeito da tremenda expansão do conhecimento humano, um paradoxal imediatismo escolar reduziu a duração dos cursos e do dia escolar a fim de oferecer a um maior número de alunos uma educação primária reduzida ao mínimo.

Isso posto, passamos ao recorte deste artigo, compartilhando parte dos debates sobre a estratégia de Educação Integral, engendrada pelo Programa Mais Educação, que é desenvolvido pelo Ministério da Educação em parceria com Estados e Municípios; e que materializa a inclusão da Educação Integral e em tempo integral na agenda de políticas educacionais do governo brasileiro. Em abril de 2007, no âmbito das ações do Programa de Desenvolvimento da Educação (PDE), por meio da Portaria Interministerial n. ${ }^{\circ} 17$ que teve como signatários os Ministérios da Educação, Cultura, Esporte, Desenvolvimento Social, instituiu-se o Programa Mais Educação ${ }^{4}$.

De saída, é importante considerar a distinção e a aproximação entre os conceitos de Educação Integral, conforme exposto por Ana Cavaliere (2010), e de Escola de Tempo Integral, exposto por Jaqueline Moll (2010).

Educação integral. Ação educacional que envolve diversas e abrangentes dimensões da formação dos indivíduos. Quando associada à educação não-intencional, diz respeito aos processos socializadores e formadores amplos que são praticados por todas as sociedades, por meio do conjunto de seus atores e ações, sendo uma decorrência necessária da convivência entre adultos e crianças. [...] Quando referida à educação escolar, apresenta o sentido de religação entre a ação intencional da instituição escolar e a vida no sentido amplo (CAVALIERE, 2010).

4 Para aprofundamento ver: Moll (2009a, 2009b, 2009c, 2009d). 
Escola de tempo integral. Em sentido restrito refere-se à organização escolar na qual o tempo de permanência dos estudantes se amplia para alem do turno escolar, também denominada, em alguns países, como jornada escolar completa. Em sentido amplo, abrange o debate da educação integral - consideradas as necessidades formativas nos campos cognitivo, estético, ético, lúdico, físico-motor, espiritual, entre outros no qual a categoria "tempo escolar" reveste-se de relevante significado tanto em relação a sua ampliação, quanto em relação à necessidade de sua reinvenção no cotidiano escolar (MOLL, 2010).

O recorte em questão tem como foco uma compreensão do modus operandi, para a paulatina reorganização da escola na perspectiva da Educação Integral, materializada através dos macrocampos para a oferta de atividades que expandam o horizonte formativo dos estudantes. Trata-se da proposição dos macrocampos de Educação Integral ${ }^{5}$ como um conjunto de vivências, linguagens e conhecimentos disciplinares incorporados ao currículo por legislação, por iniciativas locais, por políticas intersetoriais e outras iniciativas, que abrem possibilidades de ampliação e ressignificação do tempo diário de/na escola. Essa proposição está em curso, com o desafio de auxiliar a construção de projetos político pedagógicos de Educação Integral a partir de experiências

5 Os macrocampos em questão foram apresentados em primeira mão pela Resolução n. ${ }^{\circ} 19$, de 05 de maio de 2008 e consagrados no Decreto 7083, de 27 de janeiro de 2010: 1. Acompanhamento pedagógico. Ensino Fundamental: Matemática, Letramento Ciências, História, Geografia, Línguas Estrangeiras. Ensino Médio, Matemática, Leitura e Produção de Texto ou Português, Cinética, Reações Químicas, Eletroquímica, Química orgânica, Física ótica, Circuitos elétricos, Calorimétrica, Célula animal Estrutura do DNA; Coleta de sangue, História e Geografia, Filosofia e Sociologia, Línguas estrangeiras. 2. Meio ambiente. Com -Vidas, Agenda 21 na escola, Educação para Sustentabilidade, Horta Escolar e/ou Comunitária. 3. Esporte e lazer. Recreação e Lazer, Voleibol, Futebol, Basquete, Handebol, Tênis de Mesa, Judô, Karate, Taekwondo, Yoga, Natação, Xadrez Tradicional, Xadrez Virtual, Atletismo, Ginástica Rítmica, Corrida de Orientação, Ciclismo, Tênis de Campo, Basquete de rua, Programa Segundo Tempo. 4. Direitos Humanos. Direitos Humanos e Ambiente Escolar, Aprendizagem e Convivência. 5. Cultura e Arte. Leitura, Banda Fanfarra, Canto Coral, Hip Hop, Danças, Teatro, Pintura, Grafite, Desenho, Escultura, Percussão, Capoeira, Flauta Doce, Cineclube, Práticas Circenses, Mosaico. 6. Cultura digital. Software educacional, Informática e tecnologia da informação, Ambiente de Redes Sociais. 7. Prevenção e promoção à saúde. Alimentação saudável, saúde bucal, práticas corporais e educação do movimento saúde sexual, reprodutiva e prevenção DST/AIDS, prevenção ao uso do tabaco e outras drogas, saúde ambiental promoção da cultura de paz, prevenção às violências e acidentes, estratégias de promoção da saúde, prevenção à dengue, febre amarela, malária, hanseníase, anemia falciforme e outras, (Articulação com o Programa Saúde na Escola- MEC/MS). 8. Comunicação e uso de mídias. Jornal Escolar, Rádio Escolar, Histórias em Quadrinhos, Fotografia, Vídeo. 9. Iniciação à investigação das ciências da natureza. Laboratório, Feiras e Projetos Científicos. 10. Educação econômica. Direitos do Consumidor, Educação Financeira, Empreendedorismo, Cidadania Fiscal. 
desencadeadas no âmbito das escolas e de suas redes, para implementação de programas e projetos de Educação Integral ${ }^{6}$. Desde essas experiências consideramos apontamentos críticos e propositivos em relação à divisão da vida escolar em turnos, seus principais limites e as ações necessárias para sua superação. Trata-se do olhar, a ser desconstruído, que capta o turno fixo, em que prevalecem as disciplinas tradicionais, que constituem o núcleo duro do currículo e os contraturnos flexíveis, em que prevalecem as atividades que procuram tornar o tempo escolar agradável ${ }^{7}$. A superação dessa organização temporal e a vivência do tempo contínuo é um importante desafio a ser enfrentado e que, seguramente, acompanhará a proposição das Diretrizes Curriculares Nacionais de Educação Integral em Tempo Integral a serem propostas pelo Conselho Nacional de Educação em 2012. O pano de fundo dessas reflexões constitui-se, a partir dos movimentos realizados pelo Ministério da Educação, na implicação de diferentes atores institucionais da educação brasileira na construção de uma pauta política e pedagógica em favor da Educação Integral.

\section{Fazer caminhos ao andar...}

As políticas de Educação Integral e em tempo integral foram invocadas e retomadas, neste momento histórico, com suas condições conjunturais e estruturais, desta primeira década dos anos 2000, graças ao reconhecimento de seu papel como política positiva para enfrentamento das desigualdades sociais e, consequentemente, das desigualdades educacionais. Nesse sentido, o desenho de uma estratégia indutora, de caráter nacional e comprometida com sua exequibilidade conceitual e sustentabilidade em seu financiamento, foi realizado

6 Ver textos preliminares para a publicação Cadernos Pedagógicos de Educação Integral com as temáticas dos macrocampos: <http://portal.mec.gov.br/index.php?option=com_content\&v iew $=$ article \&id $=16727 \&$ Itemid $=1119>$.

7 Cotejamos a problemática turno e contraturno com a análise apresentada por Eva Wairos Pereira e Pedro Mesquita de Carvalho, dentre as resistências, contradições e impasses na concretização do plano de Anísio Teixeira (PEREIRA; CARVALHO, 2011, p. 103-104, grifo nosso): “[...] na Escola Classe era-lhes ministrada a educação intelectual sistemática e, em turno oposto, os mesmos alunos frequentavam a Escola Parque em atividades complementares, que visavam ao seu desenvolvimento artístico, físico e recreativo, bem como a sua iniciação ao trabalho. Configurava-se, nessa prática, a ideia de uma Educação Integral que requeria de professores e estudantes jornada de trabalho e estudos em tempo integral". 
pela Secretaria de Educação Continuada, Alfabetização e Diversidade, $\mathrm{SECAD}^{8}$ e sua implementação fez parte do escopo das tarefas da Diretoria de Educação Integral, Direitos Humanos e Cidadania. Tal desenho foi situado na amplitude e na perspectiva da diversidade e da riqueza sociocultural no país, bem como da riqueza em termos de diversidade de projetos educativos escolares e de suas múltiplas conexões com suas comunidades. No bojo desse projeto aberto, um conjunto de ideias e práticas foram mobilizadas em favor do desenho da estratégia de Educação Integral.

A diversidade cultural brasileira foi submetida historicamente a práticas homogeneizadoras e para falar desse projeto aberto, é importante lembrar a expressão de Boaventura de Souza Santos, balizadora de reflexões presentes no Texto referência para o debate nacional sobre Educação Integral (MOLL, 2009a, p. 31): "em que cada pessoa tem direito à igualdade, sempre que a diferença inferioriza e tem direito à diferença toda vez que a igualdade homogeneíza, para dar conta da complexidade do mundo contemporâneo".

Uma estratégia indutora de políticas sociais e educacionais, papel inequívoco do governo federal, auxilia a criação de novas agendas, compromissos, reflexões, práticas e debates. Essa estratégia também impõe a tarefa de sua institucionalização como política pública educacional. A portaria interministerial e o decreto presidencial mencionados, além de inúmeras resoluções, ancorados na vigente Lei de Diretrizes e Bases da Educação Nacional, produziram uma rede formal de sustentação da estratégia proposta. Nesse sentido, não se pode dissociar os processos vivenciados e sua normatização, feita tanto pela via da legislação quanto pelos modos de (re)organizar a escola, embora esses modos pareçam estar a reboque da legislação. Sendo assim, cumpre-nos destacar também que o Decreto 7.480, de 16 de maio de 2011, apresenta uma nova estrutura organizacional para o Ministério da Educação e definiu na estrutura da Secretaria de Educação Básica (SEB) o desenho da Diretoria de Currículos e Educação Integral. Como o próprio nome indica, coube a essa diretoria a gestão das ações de Educação Integral. Devemos destacar a importância dessa redefinição institucional, na medida em que traz a agenda da Educação Integral para o bojo das políticas de educação básica do Ministério da Educação, buscando superar, também, na estrutura da gestão, as possíveis e indesejadas dicotomias turno/contraturno, currículo/ações complementares.

8 Em outra oportunidade refletimos sobre a diversidade cultural como desafio para a construção e ampliação da esfera pública de direitos no Brasil, enfatizando a importância da Secad (LECLERC, 2005). 
Em relação à rede formal de sustentação para a retomada da Educação Integral na política educacional brasileira, é importante evidenciar que a Lei de Diretrizes e Bases da Educação Nacional n. ${ }^{\circ}$ 9394/1996 previu em seu artigo 34 que "a jornada escolar no ensino fundamental incluirá pelo menos quatro horas de trabalho efetivo em sala de aula, sendo progressivamente ampliado o período de permanência na escola"; e que "o ensino fundamental será ministrado progressivamente em tempo integral, a critério dos sistemas de ensino". No conjunto de suas disposições transitórias, o artigo 87 determina que "serão conjugados todos os esforços objetivando a progressão das redes escolares públicas urbanas do ensino fundamental para o regime de escolas de tempo integral”. Nessa mesma direção, o Plano Nacional de Educação (2001-2010), Lei n. $^{\circ} 10.179 / 01$, apresenta a educação em tempo integral como objetivo do Ensino Fundamental e, também, da Educação Infantil; e estabelece como meta a ampliação progressiva da jornada escolar para um período de, pelo menos, 7 horas diárias. O Fundo de Manutenção e Desenvolvimento da Educação Básica e de Valorização dos Profissionais da Educação (Lei n. ${ }^{\circ} 11.494 / 2007$ ), Fundeb, em seu décimo artigo, considera o tempo integral como um dos tipos de matrícula diferenciada nas ponderações para distribuição proporcional de recursos. Nesse horizonte inscreve-se também o projeto de lei $\mathrm{n}^{\mathrm{o}} 8.035 / 2010$, em debate no Congresso Nacional, que apresenta a proposta do Plano Nacional de Educação para o período 2011-2020 incluindo a ampliação da educação em tempo integral em uma das 20 metas propostas.

Pensando em termos de "redes de sustentação" pode-se apontar que a agenda de Educação Integral, sobretudo em relação ao modo de (re)organizar a educação escolar, pode e deve nutrir novas redes de aprendizagem e intercâmbio de ideias e práticas sociais e culturais, a partir de campos conceituais (entendidos também como ferramentas) como território e intersetorialidade. Nas palavras de Ana Clara Torres Ribeiro (1996, p. 44):

Acontece, nos lugares, a resistência ao localismo que destina aos pobres a cidadania restrita e limitada. Neles, também é possível reconhecer rugosidades impeditivas das localizações ansiadas pela ação hegemônica, o que alimenta a noção de território deverá substituir o que orienta esta ação.

Ainda nessa linha argumentativa, tal como a autora, atribuímos a Milton Santos a configuração da categoria crítica do espaço e sua relevância para a ação política. 
Pela territorialidade, manifesta-se o saber, eivado de conhecimentos pretéritos, que se aproxima das verdades físicas e do confronto, que é diário, entre fisionomia, paisagem e essência das relações sociais. [...] O saber é a força dos lugares, da mesma forma que o lugar é a seiva de diferentes saberes. Ambas as idéias, (conceitos e projetos) correspondem à tenacidade do existir, à insistência do fazer vida, à riqueza do agir realmente experimentado (RIBEIRO, 1996, p. 47).

Ao tratar sobre desafios para a gestão escolar em contextos de implementação de programas federais (LECLERC, 2010), refletimos sobre a aproximação entre os sistemas de ensino e o chão da escola, mediados pela assistência técnica e financeira do Ministério da Educação no contexto da implementação de programas. $\mathrm{O}$ aspecto central sobre o desafio aqui retomado é a compreensão do chão da escola como espaço de tensão, (re)construção, saberes e vivências, em oposição ao aspecto reducionista de certa visão que a persegue como lócus para implementação de projetos e programas alienígenas em relação ao projeto político pedagógico das redes de ensino e das escolas. As tarefas de caráter teórico-metodológico dessa compreensão são dependentes da experiência de gestão democrática, na qual, ao menos idealmente, a escola é compreendida como a primeira das esferas públicas e da qual decorrem e ascendem as demais no âmbito dos sistemas de ensino9. No bojo da gestão democrática, como tensão analítica e política, destacamos o conceito de intersetorialidade. Esse conceito pressupõe que, para além do espaço específico da sala de aula e dos espaços da escola, os espaços educativos são compreendidos naqueles espaços significativos da vida do bairro e da cidade, de modo a recriar a experiência cultural

9 Nossa referência empírica é participação nos Programas Escola Aberta e Mais Educação, convergindo trajetórias e experiências de gestões municipais, da educação popular e do movimento sindical, articuladas ao trabalho acadêmico e à escola pública. Nessa convergência reside a opção pela gestão escolar, em íntima relação com a organização dos sistemas de ensino, como objeto de estudo. Como dirigente do Sindicato dos Trabalhadores no Ensino Público de Mato Grosso (19921997), tomamos parte na proposição de ações progressivas para a regulamentação do Artigo 244 da Constituição Estadual de 1989. Esse artigo determina a integração progressiva das redes estadual e municipais em um Sistema Único de Ensino. Durante o governo Dante de Oliveira (1995-1998), no MT, criaram-se mecanismos para incorporar a população usuária da escola pública (pais, mães e estudantes) e formas de participação comunitária nas tomadas de decisão sobre as Políticas Educacionais. Não houve a regulamentação do dispositivo e os mecanismos de participação não foram consolidados (LECLERC, 2002; CARDOSO NETO, 2004). Essa experiência fortaleceu nosso entendimento de que é preciso construir processos deliberativos debaixo para cima, de outro modo pode-se incorrer em vanguardismos antipedagógicos. 
e civilizatória da humanidade nas formas de cinema, teatro, música, museu, parques, vizinhanças e outros, vivenciadas como ação curricular. De modo que:

Essa perspectiva apresenta-se na contramão da segregação em que vivem milhões de crianças, adolescentes e jovens no Brasil, desnaturalizando a compreensão de uma "educação em tempo integral" que deva ocorrer em uma "escola-instituição total". [...]

Ratifica-se, então, a idéia de ação intersetorial e de forte incidência na relação entre escola e comunidade, tendo por base a compreensão de que o projeto educativo das novas gerações deve radicar-se em um sólido compromisso entre distintos atores que compõem o território em que a instituição escolar está situada (MOLL, 2012, p. 138).

Temos destacado a relação entre os campos da proteção social, de prevenção à violência contra crianças e adolescentes, educação para os direitos humanos, sustentabilidade ambiental e os campos de proposição da permanência na escola com aprendizagem (MOLL; LECLERC, 2010). Esse destaque se deve ao reconhecimento da escola como "expressão do público/estatal na comunidade", particularmente em contextos "em que não há posto de saúde, não há posto policial, não há nenhuma outra expressão da presença do Estado. Também não há igreja, clube de futebol ou bloco carnavalesco [...]" (MOLL, 2000 , p. 32). Essa relação entre os campos de políticas públicas repercute em nossa compreensão da intersetorialidade. O conceito se aplica em contextos de proposição de políticas que procuram desconstruir o olhar generalizado, segundo o qual a insegurança, o medo e os perigos acabam por definir a cidade. Em nossa trajetória procuramos responder positivamente às questões:

É possível que a cidade desenvolva para além de suas tradicionais funções econômicas, sociais, políticas e de prestação de serviços, uma função educadora, no sentido do compromisso coletivo e permanente de formação, da promoção e do desenvolvimento de todos os seus habitantes - crianças, jovens e adultos? Em outras palavras, é possível pensar a cidade desde a perspectiva da educação? (MOLL, 2004, p. 41).

Não há outra chave para a convivência - enxergando-se a necessidade do respeito às diferenças ideológicas, de raça, de gênero, de classe social, de cultura e modos de viver; a inscrição das questões ambientais nos espaços de ação pessoal, comunitária e cada vez mais coletiva, o aprendizado de novas formas para as 
relações intergeracionais e de alargamento de direitos sociais. Essa chave para a convivência é a educação. Sem desconstruir esse olhar, recrudesce o isolamento no âmbito doméstico, acompanhado dos muros, cercas, grades e câmeras de monitoramento como componentes da arquitetura escolar, em particular.

\title{
Marcos do caminho percorrido
}

\begin{abstract}
Caminhante, são teus rastos o caminho, e nada mais; caminhante, não há caminho, faz-se caminho ao andar.

Ao andar faz-se o caminho, e ao olhar-se para trás vê-se a senda que jamais se há-de voltar a pisar. Caminhante, não há caminho, somente sulcos no mar
\end{abstract}

Antonio Machado

Dentre os marcos do caminho trilhado desde 2007, em relação aos movimentos realizados pelo Ministério da Educação, na implicação de diferentes atores institucionais da educação brasileira e na construção de uma pauta política e pedagógica em favor da Educação Integral, destacamos ${ }^{10}$ :

As condições para a transferência voluntária de recursos pela União: a instituição dessa estratégia indutora no âmbito do governo federal por 1 meio da Portaria Interministerial 17/2007, acompanhada das Resoluções do Programa Dinheiro Direto na Escola (PDDE), do Conselho Deliberativo do Fundo Nacional de Desenvolvimento da Educação (CD/FNDE) n. ${ }^{\circ}$ 19, de 15/05/2008; n. ${ }^{\circ} 04$, de 17/03/2009; n. ${ }^{\circ} 03$, de 01/04/2010; n. ${ }^{\circ} 20$ de 06/05/2011. A publicação anual dessa Resolução desencadeia o repasse de recursos diretamente às escolas, um processo que depende da situação das Unidades Executoras das escolas em relação à prestação de contas. Nesse mesmo expediente destaca-se a articulação do Programa Mais Educação com o Programa Nacional de Alimentação Escolar (PNAE) por meio das Resoluções n. ${ }^{\circ} 38$, de 19/08/2008; n. ${ }^{\circ} 38$ de 16/07/2009, através das quais se amplia o recurso diário per capita de alimentação para estudantes em tempo integral. A cada ano são efetuados preparativos para adesão das escolas. Em 2012, prevê-se a permanência das 15.000 escolas atuais e a expansão

10 Os destaques têm por base o debate efetuado na Reunião Técnica do Ministério da Educação com Secretarias Estaduais e Municipais de Educação realizada em dezembro de 2011 que tratou das premissas para planejamento 2012. 
para 15.000 novas escolas, dentre as quais, 5.000 escolas do campo. A adesão é feita por meio de cadastramento no Sistema Integrado de Monitoramento Execução e Controle (SIMEC). Ainda em 2012, dentre os preparativos, destaca-se o alcance de cinco mil escolas públicas brasileiras a implementar o Programa Escola Aberta ${ }^{11}$. O Programa Escola Aberta será expandido paulatinamente para as redes de ensino que já oferecem o Programa Mais Educação. Na abertura das escolas aos finais de semana destaca-se a relação escola-comunidade, como aspecto da qualificação do ambiente escolar.

A construção de estratégias comunicativas presenciais e virtuais com as secretarias de educação e suas redes de ensino: a tessitura institucional que tem permitido a construção de redes de apoio e de execução do Programa Mais Educação, na perspectiva da Educação Integral em tempo integral, implica um esforço permanente de diálogo entre o MEC, as equipes gestoras do Programa Mais Educação nos estados e municípios e as próprias escolas. Partindo desse pressuposto, inúmeros seminários, reuniões, encontros e fóruns locais, regionais, estaduais e nacionais para o debate da Educação Integral têm sido organizados, socializando pautas que têm tecido os fios da história da educação brasileira e seus pressupostos filosóficos e pedagógicos na perspectiva de uma educação emancipatória. Tais espaços de debate, organizados ou não pelo MEC, têm abordado também temáticas relativas à operacionalização e materialização da Educação Integral em tempo integral como a infraestrutura das escolas, oferta de cozinhas e refeitórios adequados para o fornecimento de, no mínimo, três refeições diárias, vestiários e banheiros; nutricionistas para elaborar o cardápio conforme o Programa Nacional de Alimentação Escolar; cumprimento das sete horas diárias, 5 dias por semana, conforme O Plano Nacional de Educação, Lei n. ${ }^{\circ} 10.172 / 01$, com previsão de professores e funcionários em número suficiente; disponibilização de um coordenador por escola (Professor Comunitário); participação do Coordenador do Programa na Secretaria de Educação no Grupo de Trabalho Intersetorial do Programa Saúde na Escola. Como a adesão ao Programa é feita anualmente e a cada ano o programa é expandido, os eventos em pauta buscam contemplar os diferentes ciclos da implementação do Programa Mais Educação, representados nas temáticas, problemas e propostas. Desde questões sobre como organizar a escola sob o pressuposto da formação das turmas sob a lógica de agregar diferentes idades e anos escolares, as regras e rotinas para

11 O Programa Escola Aberta: educação, cultura, esporte e trabalho para a juventude foi criado por meio da Resolução/CD/FNDE/ $\mathrm{N}^{\circ} 052$, de 25 de outubro de 2004, operacionalizado por meio do Programa Dinheiro Direto na Escola para ampliar o escopo das atividades da escola com a participação da comunidade, graças a um conjunto de estratégias que possibilitam a abertura das escolas aos finais de semana. 
uso dos materiais financiados pelo PDDE e a destinação de recursos de custeio para atividades que ainda são novidades na escola, notadamente as visitas in loco e as aulas de campo; até o debate sobre o fortalecimento institucional das ações indutoras da política de Educação Integral, mediante diferentes cenários da política educacional, financiamento e gestão, direitos humanos, articulação da Educação Integral com sistema nacional de atendimento socioeducativo e outros.

Compõe também esse esforço de diálogo permanente a organização, com frequência regular, de webvideoconferências, realizadas no MEC, que permitem colocar em rede praticamente todo território nacional. Vinte e seis webvideoconferências foram realizadas de 2008 a dezembro de 2011, materializando uma possibilidade, inusitada para muitos, de interação virtual envolvendo as 27 unidades da federação. As webvideoconferências apresentam para debate as temáticas de execução do programa, bem como as pautas que paulatinamente vão sendo criadas e agregadas no processo de expansão e qualificação do Programa Mais Educação, tais como: interfaces com os Programas Saúde na Escola, Escola Aberta, Segundo Tempo; plano de atendimento e prestação de contas; execução do Programa Dinheiro Direto na Escola; espaços físicos das escolas, relação com a comunidade e espaços das cidades para desenvolvimento das atividades de Educação Integral; Sistema Integrado de Monitoramento, Execução e Controle do Ministério de Educação; questões operacionais para o processo de adesão e preenchimento do plano de atendimento em contextos de expansão; orientações para cômputo das matrículas de tempo integral e censo escolar; etc. Além disso, as webvideoconferências têm representado momentos importantes para a explicitação e o debate dos princípios pedagógicos e curriculares que sustentam a implementação dessa estratégia ${ }^{12}$.

Capilarização do debate na sociedade brasileira: a preocupação com o aspecto do debate público está presente desde a constituição, em 2007, do Grupo de Trabalho constituído para produzir o Texto Referência Nacional para o debate da Educação Integral, com a participação de gestores e educadores municipais, estaduais, e federais, representantes da União Nacional dos Dirigentes Municipais de Educação (Undime), do Conselho Nacional dos Secretários de Educação (Consed), da Confederação Nacional dos Trabalhadores em Educação (CNTE), da Associação Nacional pela Formação de Profissionais da Educação (ANFOPE), de organizações não governamentais comprometidas com a educação, de universidades. O leque de interlocutores institucionais é constantemente ampliado, por meio de participação de interlocutores de Comissões de Educação

12 Encontram-se disponíveis no link, a partir da $4 .{ }^{a}$ webconferência $<$ http://portal.mec.gov. br/index.php?option $=$ com_content\&view $=$ article\&id $=16664 \&$ Itemid $=1110>$. 
das diferentes esferas legislativas, Conselhos de Educação e demais representações da sociedade civil. A pauta do projeto de lei 8073/2010 tem fortalecido essa interlocução institucional apontando para importantes repercussões nos Planos Estaduais e Municipais de Educação que deverão incorporar a temática da Educação Integral e em tempo integral.

Pedagogia, arquitetura e urbanismo: o Programa Mais Educação problematiza, em seu processo de execução, a questão sobre como a escola tem se organizado em relação à estrutura física e na articulação com outros espaços para ampliação de tempos, territórios e oportunidades educativas na perspectiva de Educação Integral. Um impasse reconhecido em seu processo de implementação é representado nessa questão. Em que pesem as respostas que vêm sendo apresentadas, através do Plano de Ações Articuladas (PAR) e do Plano de Aceleração do Crescimento (PAC) ${ }^{13}$ em termos do investimentos na infraestrutura das escolas, forte reivindicação das próprias escolas, a tensão também explicita a necessidade de revisão e reorganização dos usos dos espaços dentro e fora da escola. Essa demanda é o desafio a ser tratado pelo Grupo de Trabalho para definição de orientações e diretrizes para construção, reforma, ampliação e adaptações de escolas de tempo integral; instituído por meio da Portaria Normativa do Ministério da Educação n. ${ }^{\circ}$ 20, de 06/10/2011.

Territorialidade da oferta de Educação Integral em articulação com o Programa Bolsa Família (PBF): para a adesão de 2012, o MEC, em parceria com o Ministério do Desenvolvimento Social e Combate à Fome (MDS), estipulou como critério central de expansão do Programa Mais Educação a seleção de escolas em que a maioria dos alunos faça parte de famílias beneficiárias do PBF. O debate sobre esse processo de articulação interministerial, portanto intersetorial, foi desencadeado em Reunião Técnica, realizada em Brasília, em dezembro de 2011, com a participação de dez coordenadores estaduais do $\mathrm{PBF}^{14}$ e representantes estaduais e municipais dos programas de Educação Integral aqui tratados. Tal ação retoma o aspecto, presente na estratégia desencadeada pelo Programa Mais Educação, de enfrentamento das profundas desigualdades educacionais ainda presentes no país. Ao constituir-se, preferencialmente, nas escolas das regiões mais periféricas, mais vulneráveis, mais violentas estabelece uma perspectiva de

13 No âmbito específico do PAC aponta-se a construção e cobertura de quadras poliesportivas. Ambos planos mencionados podem ter suas ações verificadas no sítio <www.mec.gov.br>.

14 Amazonas, Pará, Ceará, Bahia, Alagoas, Piauí, Sergipe, Pernambuco, Maranhão, Minas Gerais. Ver ainda Nota Técnica n. ${ }^{\circ} 192$, produzida com acordo entre a Diretoria de Condicionalidades, da Secretaria Nacional de Renda de Cidadania, do Ministério do Desenvolvimento Social e Combate à Fome e a Diretoria de Educação Integral e Currículos, da Secretaria de Educação Básica, do Ministério da Educação. 
discriminação positiva, na medida em que essas escolas recebem aportes orçamentários diferenciados, bem como são prioritárias na relação com as universidades interlocutoras em ações de formação para a docência e a gestão.

Tecer redes humanas e redes institucionais: Trata-se do esforço necessário para embasar a força da política pública que está nascendo nos processos e movimentos sociais que convergem ações de Educação Integral e aspirações por uma escola republicana, democrática, de qualidade, renovada e reinventada. Esse não é um movimento debutante, trata-se de dar visibilidade à emergência de processos que vitalizam a educação pública sob outras condições históricas com as temáticas de financiamento, gestão, piso salarial profissional nacional dos trabalhadores da educação, carreira, formação continuada; e no âmbito da profissionalização evidenciar, ao lado da docência, o papel educativo dos demais profissionais que sempre atuaram na escola e que são destacados pelo fato de a Educação Integral pautar a requalificação do ambiente escolar. A tensão desse debate é anterior às iniciativas para ampliar o tempo diário letivo. Nesse processo, destaca-se a construção da autonomia da escola, a relação escola e comunidade; a proposição de novos arranjos educativos considerando diferentes coletivos em interação, nos espaços educativos dentro e fora da escola. Destaca-se nesse aspecto a organização de Comitês Metropolitanos ou Regionais ou Estaduais ou Interestaduais de Educação Integral que têm sido constituídos país afora articulando gestores municipais e estaduais de educação e de outras políticas sociais, gestores escolares, associações de pais e professores, universidades, entre outros atores, em um esforço conjunto para compreensão, debate e enfrentamento dos desafios da agenda da Educação Integral.

Relação orgânica das políticas curriculares e proposição das diretrizes curriculares nacionais de Educação Integral: do exposto, apontamos a situação e os desafios advindos da alfabetização no primeiro ciclo do ensino fundamental, dos jovens de 15 a 17 anos retidos no ensino fundamental, das Escolas de Fronteira, da Escola Aberta e do Ensino Médio Inovador como tarefas que nos impõem um fazer orgânico nessa ação indutora. Portanto, a experiência constituída em termos de ampliação de jornada escolar, nestes anos de trabalho no Programa Mais Educação, pode ser enriquecedora tanto do ponto de vista da construção compartilhada de uma política pública, quanto em relação aos inéditos viáveis produzidos em termos de currículo escolar com a legitimação de saberes e práticas sociais e culturais "normalmente" estranhas à escola. Nesse sentido, falamos em tempo ampliado e qualificado como aquele que explicita e articula atividades educativas diferenciadas e que, ao fazê-lo, contribui para a formação integral do aluno, para a superação da fragmentação e do estreitamento curricular e da lógica educativa demarcada por espaços físicos e tempos delimitados rigidamente, nos diferentes momentos da sua trajetória pela educação 
básica. Nesse sentido, entende-se que a extensão do tempo - quantidade - deve ser acompanhada por uma intensidade do tempo - qualidade - nas atividades que constituem a jornada ampliada na instituição escolar (MOLL, 2009a). A proposição das Diretrizes Curriculares Nacionais de Educação Integral, em construção pelo Conselho Nacional de Educação, constituir-se-á em referência normativa e pedagógica para o campo.

\section{À guisa de conclusão}

Não será essa escola, de quatro e até três horas diárias, parada mais de três meses ao ano [...], escola perdida, toda ela, ou quase toda ela, no nervosismo imposto pelo cumprimento dos programas, feitos às vezes até revelando certa intimidade com problemas locais e regionais mas, cedo "verbalizados", transformados assim em noções que se ditam e impõem aos educandos, que irá integrar esse educando academizado com as realidades [...]. Escola que, diminuída no seu tempo, está intimamente ligada à falsa concepção que temos de sua instrumentalidade [...] (FREIRE, 2002, p. 88).

A instalação do sistema escolar no Brasil com suas condições históricas, econômicas, socioculturais e geográficas foi feita por meio do desdobramento de turnos (SOUZA,1998). As classes médias sempre pagaram a complementação do turno escolar de suas crianças e jovens com atividades artísticas, de lazer, línguas estrangeiras e fruição de vivências culturais. Mesmo nos contextos de desigualdade a escola pública, por iniciativas e esforços próprios, também é marcada por iniciativas de complementação das atividades escolares. Nesses casos ela está, em geral, apoiada por um conjunto de práticas sociais e comunitárias. O esforço realizado na construção de uma agenda propositiva para uma política de Educação Integral, tendo por base a estratégia indutora nacional representada pelo Programa Mais Educação, tem explicitado, em seus avanços e desafios, questionamentos, reflexões e novas práticas acerca da necessária reorganização curricular em tempos ampliados. Tal processo ganha significado diferenciado quando o acúmulo de experiências que dialogam com as culturas populares, juvenis e infantis, começa a ganhar espaço no cotidiano das escolas. A definição 
do projeto político pedagógico da escola para superar a fragmentação, a descontextualização dos conteúdos, a gestão antidemocrática e, na sua contramão, estreitar a relação entre escola e comunidade é o caminho para a proposição de novas diretrizes e novas lógicas ampliadoras de tempos, espaços educativos e mobilização comunitária. A oferta de atividades diferenciadas no turno oposto às aulas apresenta limites para a efetivação do projeto político pedagógico, por isso, requer a superação do dualismo turno e contraturno. Essa reorganização curricular está implicada no fato de que as atividades diferenciadas não têm o mesmo peso dos conteúdos tradicionalmente compreendidos como escolares. Antes disso, o currículo escolar se configura como de tensão e de seleção cultural, que prioriza alguns aspectos da cultura em detrimento de outros. A articulação das atividades diferenciadas e de abertura das escolas aos finais de semana com a organização curricular não se limita a incluir as oficinas na grade curricular oficial, transformando-as em outras disciplinas curriculares, entendidas, muitas vezes, como de menor valor. Essa superação requer o reconhecimento de novas dimensões da formação docente, o debate sobre conteúdos escolares consagrados no currículo e os que ainda são considerados "extraescolares". Assim, a entrada das atividades de arte, capoeira, hip hop, jornal e rádio escolar, direitos humanos, sustentabilidade ambiental, entre tantas outras, pode ser compreendida como expressão das inúmeras possibilidades de vivências ampliadoras das dimensões da formação humana, segundo a compreensão do projeto político pedagógico em que estão sendo inseridas. Essa compreensão pode exigir outras lógicas de agrupamento, outras formas de articulação entre saberes, outros usos do tempo e outros espaços, outra relação entre cultura acadêmica e cultura da experiência, outras demandas de formação, novas materialidades que coloquem educação corporal, educação ambiental, arte-educação dentre os conteúdos preciosos do currículo. Tais horizontes ampliados colocam-se na relação direta com o enfrentamento de uma lógica perversa e seletiva que continua a atravessar os sistemas de ensino, distribuindo de forma desigual, e em condições desiguais, saberes e oportunidades. Uma Educação Integral em uma escola de tempo integral pode efetivamente apontar as condições diferenciadas para que acessem, permaneçam e aprendam no interior das escolas, aquelas crianças e jovens cujos pais foram excluídos e esquecidos, em função da obrigação de produzir sua vida material, reproduzindo eles mesmos a condição de seus pais e avós nas regiões mais pobres do país. 


\section{REFERÊNCIAS}

CARDOSO NETO, Odorico. Dissenso no consenso: a democratização da escola pública em Mato Grosso. Cuiabá: Editora da UFMT, 2004.

CAVALIERE, Ana Maria. Educação Integral. In: OLIVEIRA, Dalila Andrade. et al. Dicionário trabalho, profissão e condição docente. Belo Horizonte: UFMG/Faculdade de Educação, 2010, CD ROM.

COETZEE, J. M. Diário de um ano ruim. São Paulo: Companhia das Letras, 2008.

FREIRE, Paulo Reglus Neves. Educação e atualidade brasileira. São Paulo: Cortez, 2002.

LECLERC, Gesuína de Fátima Elias. Sistema único de ensino: o desafio da construção e da ampliação do espaço público de direitos na escola pública de Mato Grosso. Educação e Sociedade, v. 23, n. 78, p. 199-222, 2002.

. Cultural diversity as a challenge for the construction and enlagement of the public sphere of rights in Brazil. BEST - Black European Studies, 2005. Disponível em: $<$ http://www.best.uni-mainz.de/modules/AMS/article.php?storyid=102>. Acesso em: 18/9/2012.

. Desafios para a gestão escolar em contextos de implementação de programas federais. In: SEMINÁRIO INTERNACIONAL DE GESTÃO EDUCACIONAL, 2.; e SEMANA ACADÊMICA DO CURSO DE ESPECIALIZAÇÃO EM GESTÃO EDUCACIONAL, 4., 2010, Santa Maria. Políticas públicas e gestão: caminhos e descaminhos. Santa Maria: UFSM, 2010. p. 01-10.

MOLL, Jaqueline. Histórias de vida, histórias de escola: elementos para uma pedagogia da cidade. Petrópolis: Vozes, 2000.

. A cidade educadora como possibilidade - apontamentos. In: TOLEDO, Leslie; FLORES, Maria Rodrigues; CONZATTI, Marli (Orgs.). Cidade Educadora: a experiência de Porto Alegre. São Paulo: Cortez, Instituto Paulo Freire; Buenos Aires: Ciudades Educadoras, America Latina, 2004. p. 39-46.

. (Org.). Educação Integral: texto referência para o debate nacional. Brasília: MEClSecad, 2009a. Disponível em:. <http://portal.mec.gov.br/dmdocuments/cadfinal_ educ_integral.pdf $>$. Acesso em: 18/9/2012.

Gestão intersetorial no território. Brasília: MEC/Secad/Cenpec, 2009b. Disponível em: $<$ http://portal.mec.gov.br/dmdocuments/cader_maiseducacao_2.pdf $>$. Acesso em: 18/9/2012. 
. Redes de saberes. Pressupostos para projetos político pedagógicos. Brasília: MEC/Secad, 2009c. Disponível em: <http://portal.mec.gov.br/dmdocuments/cad_mais educacao_2.pdf $>$. Acesso em: 18/9/2012.

. Programa Mais Educação: passo a passo. Brasília, MEC/Secad, 2009d. Disponível em: <http://portal.mec.gov.br/dmdocuments/passoapasso_maiseducacao. pdf $>$. Acesso em: 18/9/2012.

. Escola de tempo integral. In: OLIVEIRA, Dalila Andrade. et al. Dicionário trabalho, profissão e condição docente. Belo Horizonte: UFMG/Faculdade de Educação, 2010, CD ROM.

. A agenda da educação integral: compromissos para sua consolidação como política pública. In: MOLL, Jaqueline. et al. Caminhos da educação integral no Brasil: direito a outros tempos e espaços educativos. Porto Alegre: Penso, 2012. p. 129-143.

MOLL, Jaqueline; LECLERC, Gesuína de Fátima Elias. Educação Integral e Comunitária: o remirar-se da cidade e da escola In: PADILHA, Paulo Roberto; CECCON, Sheila; RAMALHO, Priscila. Município que educa: múltiplos olhares. São Paulo: Editora e Livraria Instituto Paulo Freire, 2010. p. 51-57.

PEREIRA, Eva Wairos; CARVALHO, Pedro Mesquita. Resistência, contradições e impasses na concretização do plano de Anísio Teixeira. In: PEREIRA, Eva Wairos. et al. Nas Asas de Brasília: memórias de uma utopia educativa (1956-1964). Brasília: Universidade de Brasília, 2011. p. 103-120.

REIS FILHO, Casemiro dos. A Educação e a ilusão liberal: origens da escola pública paulista. Campinas: Autores Associados, 1995.

RIBEIRO, Ana Clara Torres. Lugares dos saberes: diálogos abertos. In: BRANDÃO, Maria A. Milton Santos e o Brasil: território, lugares e saber. São Paulo: Fundação Perseu Abramo, 1996. p. 39-56.

SOUZA, Rosa Fátima de. Templos de civilização: a implantação da escola primária graduada no Estado de São Paulo (1890-1910). São Paulo: UNESP, 1998.

TEIXEIRA, Anísio. Educação não é privilégio. Rio de Janeiro: Editora da UFRJ, 2007. (Coleção Anísio Teixeira).

Texto recebido em 23 de março de 2012.

Texto aprovado em 04 de maio de 2012. 